\title{
EL MUSEO PACHACAMAC EN EL SIGLO XXI
}

\author{
THE PACHACAMAC MUSEUM IN THE XXI CENTURY
}

\author{
Denise Pozzi-Escot ${ }^{1}$ y Carmen Rosa Uceda ${ }^{2}$
}

\begin{abstract}
Bajando por los valles desde las alturas de los Andes hacia el mar, o caminando por el litoral, la visita al sitio arqueológico de Pachacamac, lugar sacralizado o santuario, el más importante de la costa peruana prehispánica, se convirtió en un ritual fundamental de peregrinaje. El nuevo museo de sitio ha significado un esfuerzo del Ministerio de Cultura del Perú para ofrecer al público un museo que reúna las condiciones adecuadas para la conservación, preservación y difusión de la riqueza cultural que encierra. Es uno de los museos más visitado del país y el público objetivo, en el cual se pone especial interés, son las poblaciones de escasos recursos que circundan los límites del sitio arqueológico. Siguiendo las pautas del Plan de Manejo la gestión del santuario propone la participación de la población ubicada en su entorno, en beneficio de la conservación del complejo arqueológico. Por ello, el museo ha implementado un Programa de Desarrollo Comunitario, donde un grupo de mujeres que han sido capacitadas, elaboran productos utilizando la iconografía del santuario para la venta en la tienda del museo. El proyecto Educativo convoca a los niños de las escuelas promoviendo el fortalecimiento de la identidad y compromiso con el patrimonio.
\end{abstract}

Palabras claves: patrimonio arqueológico, participación, identidad, conservación.

Whether coming down through the valleys from the heights of the Andes or walking along the coast, a visit to the temples at the Pachacamac archaeological site, the most important sacred space or sanctuary on the pre-Hispanic coast, has become a fundamental ritual pilgrimage. The new site museum has meant an effort on the part of the Ministry of Culture of Perú to offer the public a museum that will provide the appropriate conditions for the conservation, preservation and promotion of the cultural wealth it contains. This is one of the most visited museums in the country and the target audience, on which a special emphasis is placed, is the economically depressed population which surrounds the archaeological site. Following the guidelines set by the Management Plan, the museum's management proposes the inclusion of the people located in its immediate surroundings through their active participation for the benefit of the archaeological site and its conservation. To this end, the museum has implemented a Community Development Program, in which a group of women that have been trained create products using the iconography of the sanctuary for its sale in the museum. The Educational project works with school children in promoting and strengthening the identity and the engagement with heritage.

Key words: Archaeological heritage, participation, identity, conservation.

El sitio arqueológico de Pachacamac fue durante la época prehispánica el más importante centro ceremonial de la costa central peruana, luego de que los incas conquistaran este territorio. Su historia conjuga tanto los procesos de desarrollo local en las cuencas de los vecinos ríos Lurín, Rímac y Chillón, como elementos regionales y panandinos. Por lo tanto, el monumento arqueológico es el resultado de los altos niveles de desarrollo alcanzado por los pueblos que le dieron origen.

A $30 \mathrm{~km}$ al sur de la ciudad de Lima, en la margen derecha del río Lurín, se ubica el sitio arqueológico de Pachacamac el cual alberga más de 50 edificios prehispánicos que resumen aproximadamente mil doscientos años de historia, construidos sobre una explanada dominada por cuatro promontorios rocosos con depósitos de arena eólica, muy cerca de la desembocadura de ese río. El clima de la zona es característico de la costa central del Perú: árido, semicálido y húmedo, propio de las tierras que se encuentran a proximidad del litoral marítimo (Figura 1).

El dios Pachacamac era una deidad religiosa, representada al parecer en el llamado hoy ídolo de Pachacamac -pieza emblemática actualmente en exposición en el museo- excepcional talla de madera que lleva un personaje bifronte en la parte superior y bajo él se desarrolla una escena compleja de tallas de carácter sagrado. Era adorado y temido en toda la

\footnotetext{
${ }^{1}$ Directora del Museo de Sitio Pachacamac, Antigua Panamericana Sur Km 31,5 - Lurín, Lima, Perú. denisepozziescot@yahoo.es

2 Arquitecta del Museo de Sitio Pachacamac, Antigua Panamericana Sur Km 31,5 - Lurín, Lima, Perú. cruceda7@ hotmail.com
}

Recibido: enero 2018. Aceptado: diciembre 2018.

http://dx.doi.org/10.4067/S0717-73562019005001404. Publicado en línea: 5-julio-2019. 


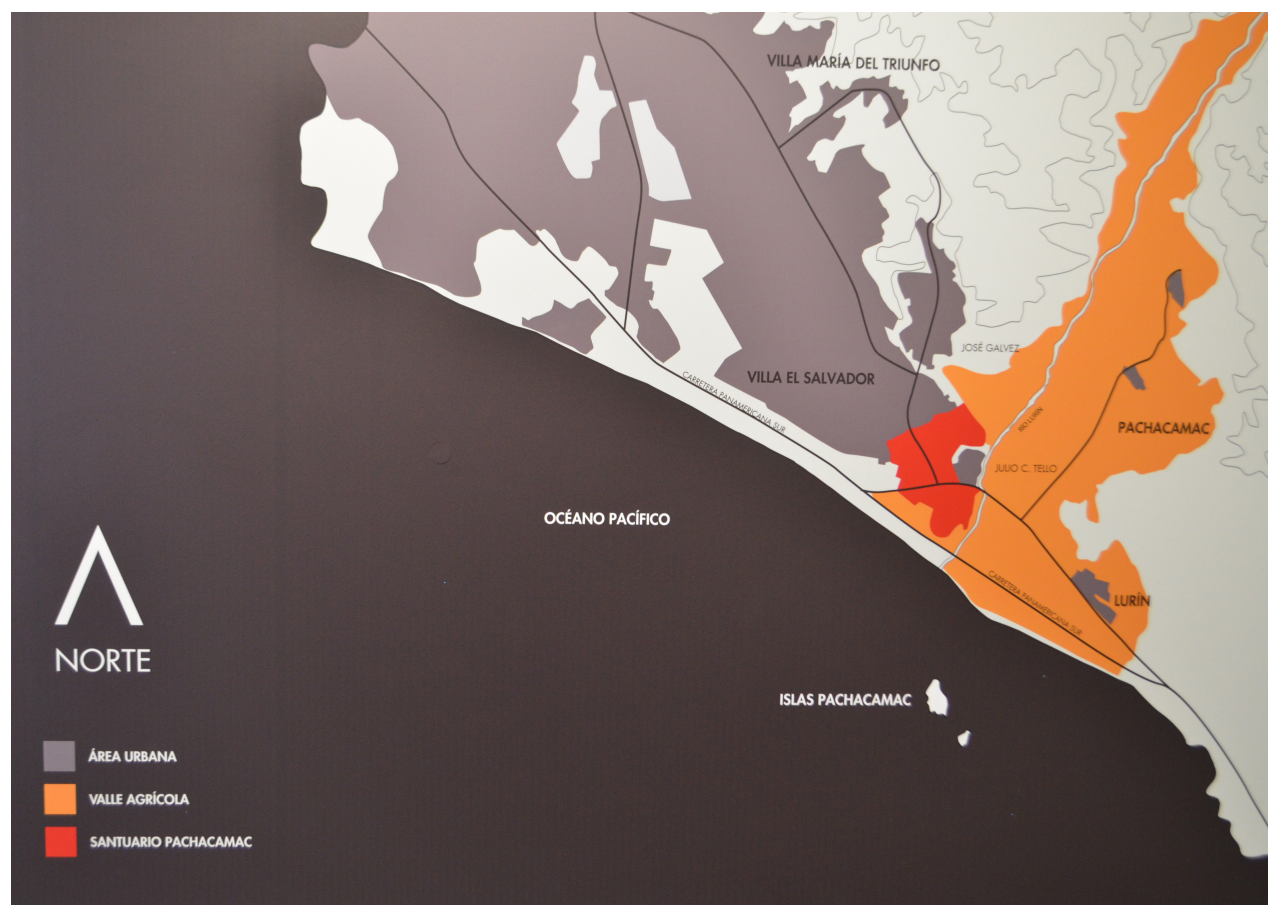

Figura 1. Plano de ubicación del santuario de Pachacamac. Archivo Museo de sitio Pachacamac.

Location Map of the Pachacamac sanctuary. Pachacamac Site Museum Archive.

costa por ser la deidad de la noche y de los temblores, atributos que configuraron su fama. Debido al poder y prestigio que tenía el dios Pachacamac, a él confluía gente de todo el imperio y gobernantes a través del Qhapaq Nan o gran camino inca, el cual tuvo un papel articulador importante en la región andina. Pachacamac fue respetado por todos los gobernantes del Tawantinsuyu, el mayor imperio en América andina cuyo centro administrativo se encontraba en el Cusco.

El sitio arqueológico de Pachacamac fue un lugar de encuentro, de integración, donde se relacionaban las poblaciones de nuestra compleja geografía.

Durante los primeros siglos de nuestra era, que corresponden a la ocupación Lima (200-600 DC) del sitio arqueológico, surgieron las primeras edificaciones dentro del área monumental, -el Templo Viejo (PozziEscot 2017:10), así como el Templo de Urpiwachaq- y el Conjunto de Adobes Lima. Estos edificios fueron hechos íntegramente de adobes pequeños, y fueron conocidos también como "adobitos" (Pozzi-Escot 2017:9).

Entre 600 y 1100 DC, durante la expansión Wari, se han podido identificar algunos cementerios de esa época que ocupan, en muchos casos, los mismos templos. Posteriormente, entre los 1100 y 1470 DC, durante el período de los Estados Regionales, se conformó el Curacazgo Ychma, que ocupaba los valles del Rímac y Lurín. Desde el sitio de Pachacamac se ejercía el control político y religioso del territorio de los Ychma y su fama ya era conocida. En este periodo se construyeron aproximadamente 16 pirámides con rampa en el sitio, arquitectura característica de esta época en la Costa Central (Pozzi-Escot 2017:14-16) (Figura 2).

Los incas conquistan la región a mediados del siglo $\mathrm{XV}$ y los principales centros urbanos son remodelados y ampliados, agregándose nuevas construcciones a partir de los patrones arquitectónicos cusqueños. Así, en lo que es hoy el sitio arqueológico de Pachacamac se construyeron varias estructuras, como el Templo del Sol y el Acllawasi o Templo de las Mamacunas (señoras de sangre noble según el Diccionario de Gonzales de Holguín). En esta época, el centro ceremonial de Pachacamac amplió significativamente su prestigio (Pozzi-Escot 2017:24).

El santuario perdió su poder de atracción solamente con la llegada de los españoles, pero en décadas recientes se observan en él importantes actividades rituales, realizadas por grupos organizados que continúan respetando, demostrada en los solsticios de invierno y verano a través de "pagos" a la tierra, lo que refleja la importancia que tiene como patrimonio nacional material e inmaterial.

\section{El Nuevo Museo de Sitio}

Al celebrarse 50 años de la creación del Museo de Sitio Pachacamac en 1965 por Arturo Jiménez Borja, se 


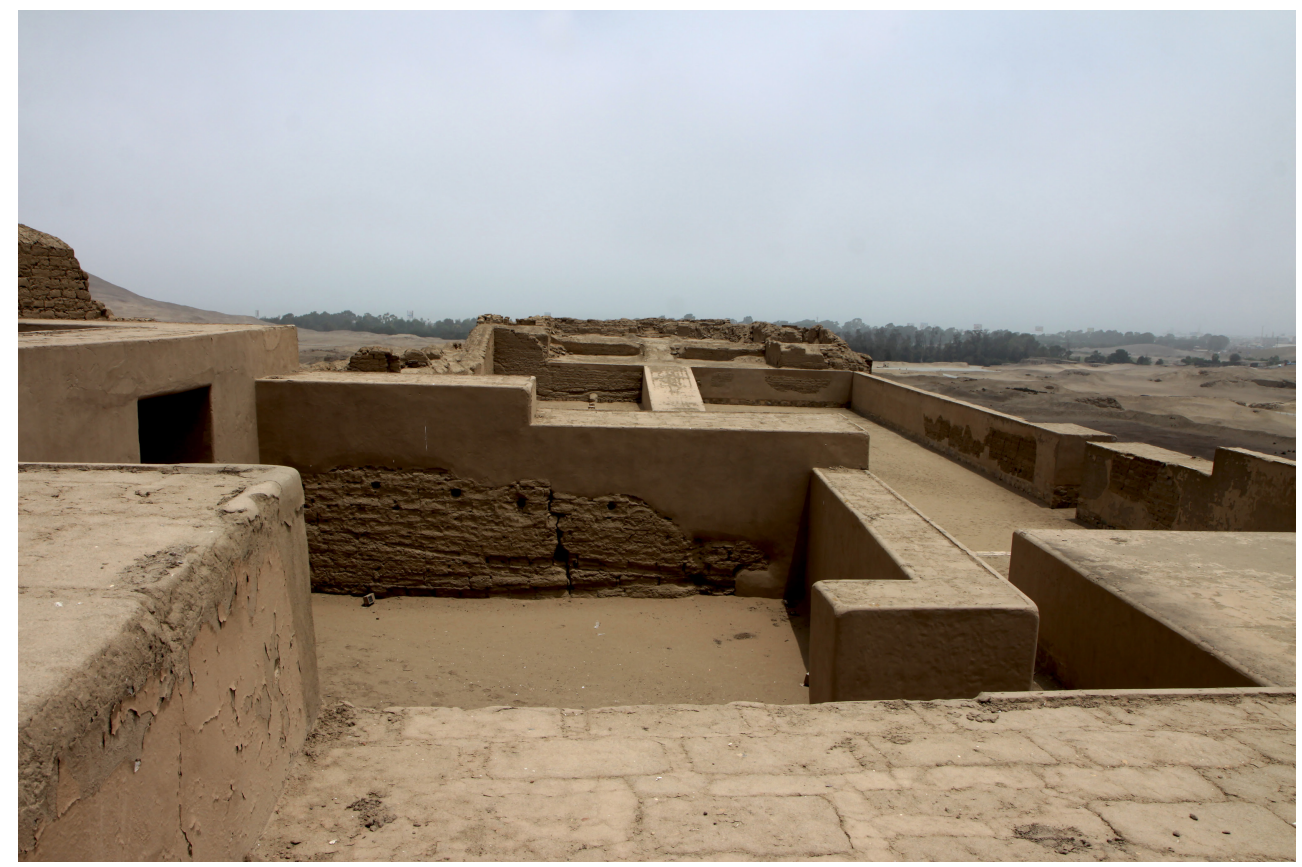

Figura 2. Pirámide con rampa 2 - Pachacamac. Foto: Rommel Angeles Falcón.

Pyramid with ramp 2 - Pachacamac. Photo: Rommel Angeles Falcón.

reinauguró el nuevo museo en febrero del 2016, inmerso en el sitio y sin restarle importancia, el cual tiene la misión de promover la valoración del sitio arqueológico de Pachacamac en la comunidad nacional e internacional (Swain 2007:246). El nuevo museo trabaja para lograr un diálogo con la población local, para consensuar y concienciar las posibilidades reales que tienen sobre su patrimonio como herramienta de desarrollo (Figura 3).

Según la definición del ICOM "el museo es una institución al servicio de la sociedad y de su desarrollo" (ICOM 2017). ¿Qué significan esos dos términos fundamentales? Conservación, entretenimiento, educación, debate y vanguardia: todo eso, sumado a la interactividad con el público, se espera hoy de un museo.

Antesala perfecta al santuario milenario, el nuevo museo fue concebido manteniendo el equilibrio arquitectónico con el entorno existente. El proyecto del Museo Pachacamac data del 2005, cuando Luis Guillermo Lumbreras S. era director general del Instituto Nacional de Cultura del Perú (INC) y convocó a un concurso para la construcción del nuevo museo de sitio. Este concurso dio como ganador al estudio de arquitectos Llosa y Cortegana, pero el proyecto quedó en suspenso hasta el 2008, año en que Cecilia Bakula -Directora del INC- lo impulsa, y encarga su actualización y ejecución. En el 2009, los arquitectos Llosa y Cortegana se reunieron con el equipo de expertos convocados por la UNESCO para la elaboración del Plan de Manejo del Santuario Arqueológico de Pachacamac y el equipo de investigadores del Museo de Sitio de Pachacamac (MSPAC), para actualizar las funciones, para tener en cuenta las actividades que hoy se desarrollan en el museo y para considerar una proyección a futuro en depósitos de material cultural y gabinetes de investigación. La actualización del diseño significó un importante intercambio y aporte de ideas entre los proyectistas y el equipo del MSPAC, permitiendo que se ajustara a las necesidades reales del funcionamiento del museo y de sus proyecciones (Figura 4).

Es destacable que en relación a la elaboración del Plan de Manejo (2012) la metodología empleada fue especialmente participativa, generándose una serie de reuniones con los diferentes actores involucrados tanto técnicos, institucionales, como actores sociales, con especial énfasis en la participación de la comunidad del entorno, constituida por asentamientos humanos de bajos recursos económicos y por aquellas comunidades que ven en la actualidad a Pachacamac como un espacio ritual donde acuden hacer las ceremonias de pago y ofrenda a la tierra. Era importante contar con la validación del Plan de Manejo por estas comunidades para iniciar los trabajos de elaboración del guion museográfico.

Esto contribuyó a establecer zonas, espacios y discursos necesarios en la concepción del nuevo museo que permitiera la continuidad de estas actividades 


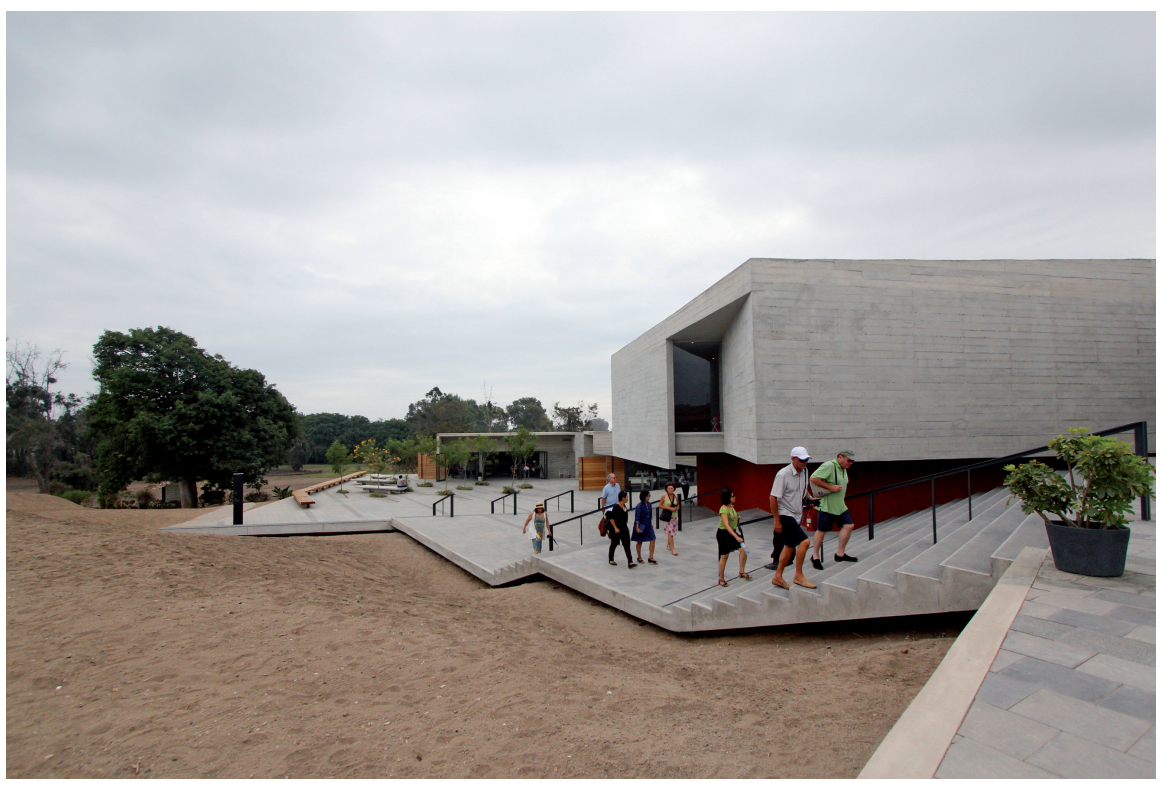

Figura 3. Fachada del nuevo Museo de sitio. Archivo Museo de sitio Pachacamac.

New site Museum. Pachacamac Site Museum Archive.

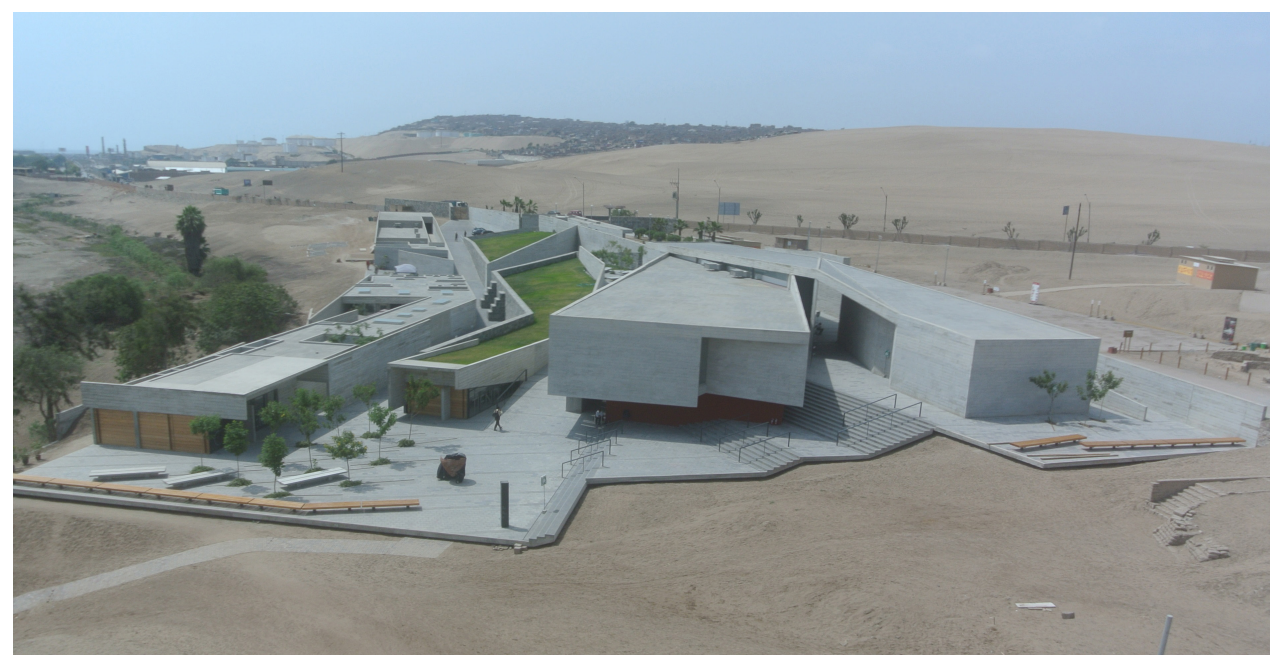

Figura 4. Edificio del nuevo Museo de sitio. Archivo Museo de sitio Pachacamac.

Building of new New site Museum. Pachacamac Site Museum Archive. 
ancestrales que hacen del santuario un espacio sagrado vivo aún en la actualidad.

El proyecto fue tomando forma y se consolidó ante su inminente construcción. Como la edificación se erigía en el mismo sitio del antiguo museo, la primera etapa significaba su demolición. Esto implicó -en el mismo lustro-, la organización del inventario, la conservación y el registro de las piezas, la cuales deberían ser trasladadas a otro lugar en condiciones adecuadas para que permanecieran allí durante la etapa de la construcción. Luego de un importante trabajo de acondicionamiento y embalaje, que dio la oportunidad de desarrollar un Protocolo de Embalaje y Traslado (Scavia 2013) las colecciones del MSPAC fueron llevadas al Museo de la Nación -Ministerio de Culturadurante un año, tiempo que duró la construcción del nuevo edificio (Figura 5).

Esta nueva realidad arquitectónica, permitió ampliar la exposición de objetos gracias a un importante incremento en el área expositiva (se contaba con 200 $\mathrm{m}^{2}$ de salas de exposiciones) y en el área de depósitos de material cultural $\left(300 \mathrm{~m}^{2}\right.$ de áreas dispersas como depósito de los materiales) Actualmente se cuenta con casi $1.000 \mathrm{~m}^{2}$ de sala de exposición permanente y temporal y $800 \mathrm{~m}^{2}$ de depósitos. En la propuesta se incrementa el área -tanto en depósitos como en salas de exposición- considerando la cantidad de material cultural existente, teniendo en cuenta que se privilegia ante todo el cuidado del patrimonio cultural, como una de las actividades más importantes que desarrollan los museos (Figura 6).

Las visiones sobre qué es hoy un museo son muchas, y abren debates que involucran cuestiones estéticas, arquitectónicas, tecnológicas y hasta geopolíticas. El impacto de la presencia del sitio arqueológico de Pachacamac, la importancia que podría representar en el desarrollo local, es especialmente reconocido por las poblaciones de los dos distritos populosos que lo rodean, Lurín y Pachacamac. Existen problemas de límites entre estos dos distritos vecinos entre sí y vecinos al sitio arqueológico, lo que en determinados momentos han significado fuertes enfrentamientos entre sus autoridades y sus habitantes, por pretender ubicar las evidencias prehispánicas dentro de sus límites, existiendo serias rivalidades que impiden conciliar acciones que les permitan un progreso en conjunto.

El MSPAC no es ajeno a estos problemas. Estamos trabajando para que de alguna manera estos conflictos políticos no enfrenten a los pobladores, y por ello ha sido importante la participación de la población de estos distritos en nuestras diferentes actividades para lograr una identificación con el sitio que van más allá de los limites distritales. El sitio arqueológico y el museo

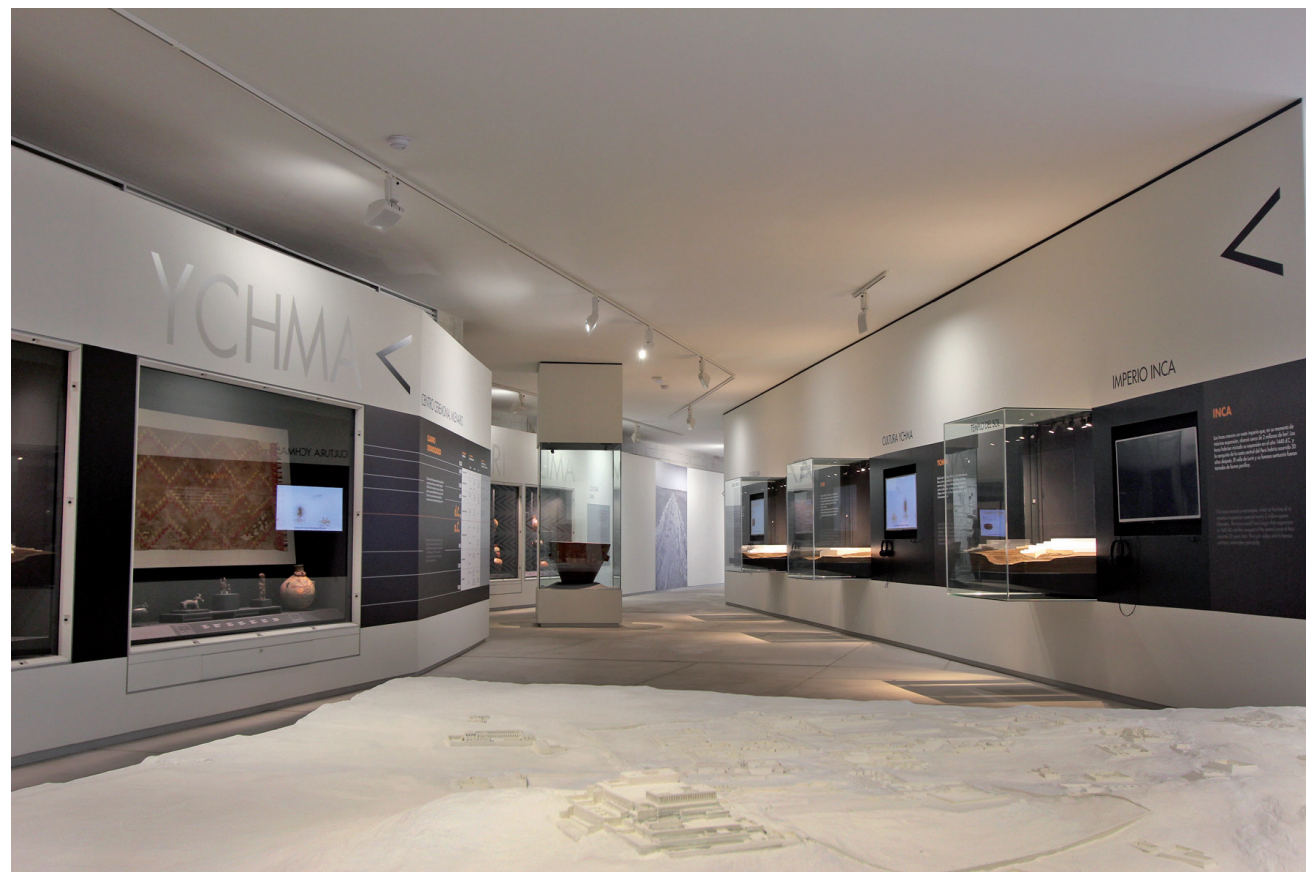

Figura 5. Vista interior del Museo. Archivo Museo de sitio Pachacamac.

Interior view of the Museum. Pachacamac Site Museum Archive. 


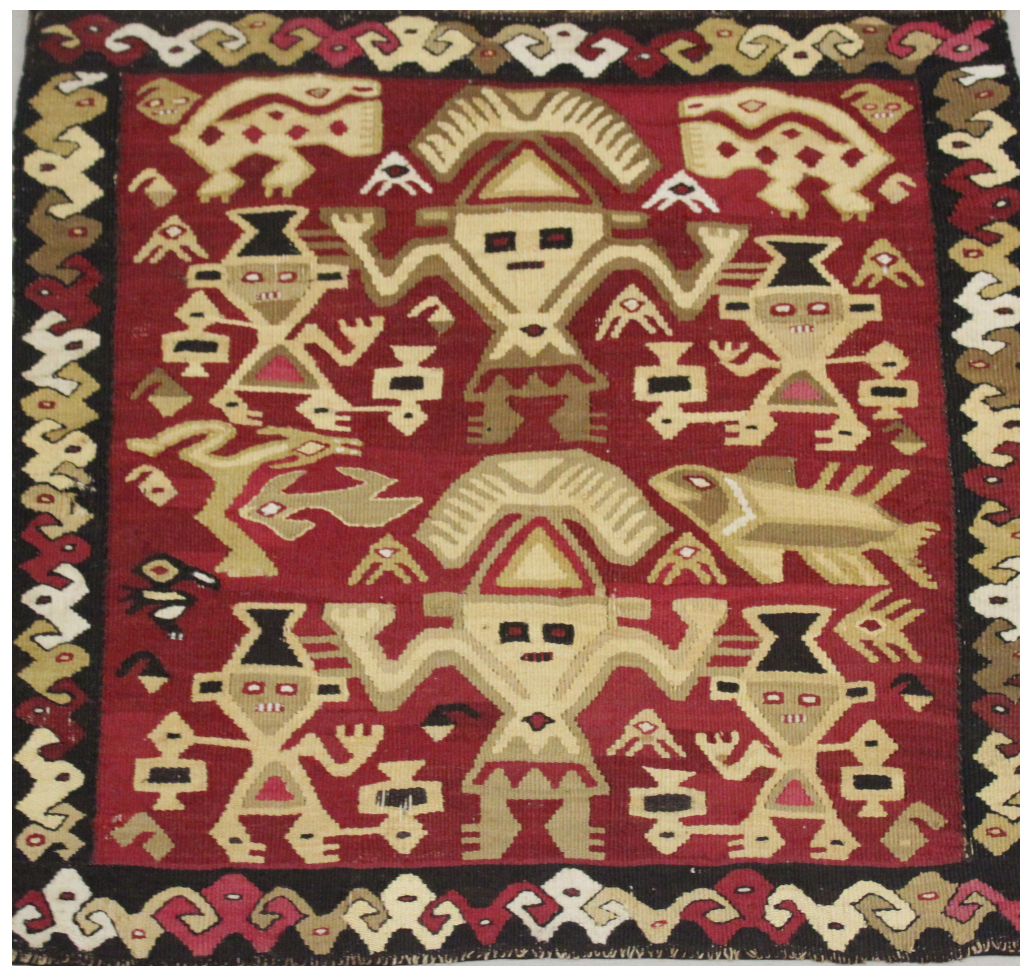

Figura 6. Paño en tapiz Ychma. Registro Nacional N 89815 . Foto: Rommel Angeles Falcón. Cloth in Ychma tapestry. National Record N89815. Photo: Rommel Angeles Falcón.

pretenden convertirse en el eje articulador de intereses comunes basados, especialmente, en el reforzamiento de la identidad y del respeto al patrimonio, promoviendo espacios de encuentro en capacitaciones y difusión y, más aún, ofreciendo oportunidades de desarrollo comunitario que les permita mejorar sus condiciones de vida.

Para la conservación y preservación de la extensa área del santuario arqueológico de Pachacamac (465 ha), ante el crecimiento de la ciudad y la presión que exigen sus habitantes por nuevos terrenos, reconocemos como fundamental la alianza con las poblaciones de escasos recursos y vecinas al sitio arqueológico, que pueda estimular el compromiso de salvaguardarlo y respetarlo.

El mayor reto es tratar de ser relevantes para la comunidad, para ello buscamos un patrimonio que "Considere sus usos sociales... con una visión más compleja de cómo la sociedad se apropia de su historia y puede involucrar a nuevos sectores" (García Canclini 1999:33).

\section{El Proyecto Museográfico}

En la segunda mitad del siglo pasado, en la región andina, al lado de los grandes museos-templo aparecen los museos de sitio, que permiten poner en valor el significado cultural de los yacimientos arqueológicos y sus hallazgos más importantes, relacionándolos a un determinado territorio, contribuyendo de esta manera a su preservación. El trabajo hoy de un museo de esta categoría va más allá del sitio mismo, abarca un territorio y tiene el deber de fomentar su función educativa y atraer a un público más amplio procedente de la comunidad, de la localidad. La interacción con la comunidad y la promoción de su patrimonio forman parte integrante de la función educativa del museo (ICOM 2017:24).

El guion museográfico está dirigido a compartir los valores que califican al sitio arqueológico de Pachacamac para ser declarado Patrimonio Cultural de la Humanidad ante la UNESCO, remarcando el tema del peregrinaje prehispánico como uno de los valores del sitio, el cual se mantiene vivo a pesar del paso del tiempo. Hoy grupos de personas recorren los senderos y espacios que lo antiguos recorrieron, con el propósito de rendir tributo al dios Pachacamac.

El guion determina 27 espacios para la exposición, que incluyen textos cortos y escritos en un lenguaje sencillo, para que sean accesibles a un público más variado. Estuvo a cargo de Marco Rosas, consultor de UNESCO para el Plan de Manejo de Pachacamac, quien trabajó con Katiusha Bernuy y Rommel Angeles del equipo del MSPAC. 
Los textos presentados sufrieron varias modificaciones, producto de largas sesiones de discusión sostenidas con el equipo de investigación del MSPAC. El museo debe de ser un espacio para todos, ya Rivière trató el tema hace mucho tiempo (Chaumier 2003:91), donde tengan cabida todas las colectividades, por eso la importancia que se le dio a los textos que se iban a exponer.

Eso implicó considerar a varios tipos de público, entre ellos, uno muy especializado y científico y otro menos formado en esas materias. La opción para el guion museográfico fue expresar de forma clara, sencilla y breve, los conceptos y la historia, priorizando a nuestro público mayoritario constituido por los niños en edad escolar (Figura 7).

El desarrollo de la síntesis fue un ejercicio arduo, pero necesario. Para el público especializado hemos elaborado una serie de cartillas que contienen información detallada de las piezas emblemáticas y complementan la información presentada en el museo.

Hoy en día no se puede desconocer la influencia de la tecnología en la facilitación de adquisición del conocimiento y disposiciones para el aprendizaje. El internet ha generado un cambio radical en todos los espacios de la humanidad y también en los espacios museísticos, facilitando en muchos casos la difusión y experimentando la información en forma diferente. Los adolescentes y jóvenes son considerados nativos digitales en cuyos contenidos de aprendizaje se incluye lo digital y lo tecnológico: software, hardware, robótica, nano-tecnología, genomas, entre otros (Prensky 2012:8). Esto constituye un importante recurso para atraer a estas nuevas generaciones al museo, y si realmente se desea contactar, comunicarse e interactuar con los nativos digitales -que son todos los que constituyen nuestra actualidad- tendrá que someterse al cambio (Prensky 2012:11).

La reciente instalación de WIFI en las salas de exposición del MSPAC ha permitido a los visitantes acceder al código QR, lo cual permite ampliar la información encontrada en el museo y puede utilizarse tanto dentro como fuera de él.

El guion museográfico ha dispuesto una secuencia, que ha sido respetada en la moderna propuesta arquitectónica, pero al mismo tiempo es flexible y se distribuye en dos espacios: uno referido a lo sagrado, y el otro relacionado a lo histórico. El arquitecto Rodolfo Cortegana fue el encargado del proyecto museográfico en diálogo constante con el equipo del museo. Se discutieron las soluciones técnicas para una adecuada presentación de los objetos, siguiendo los conceptos de la conservación preventiva.

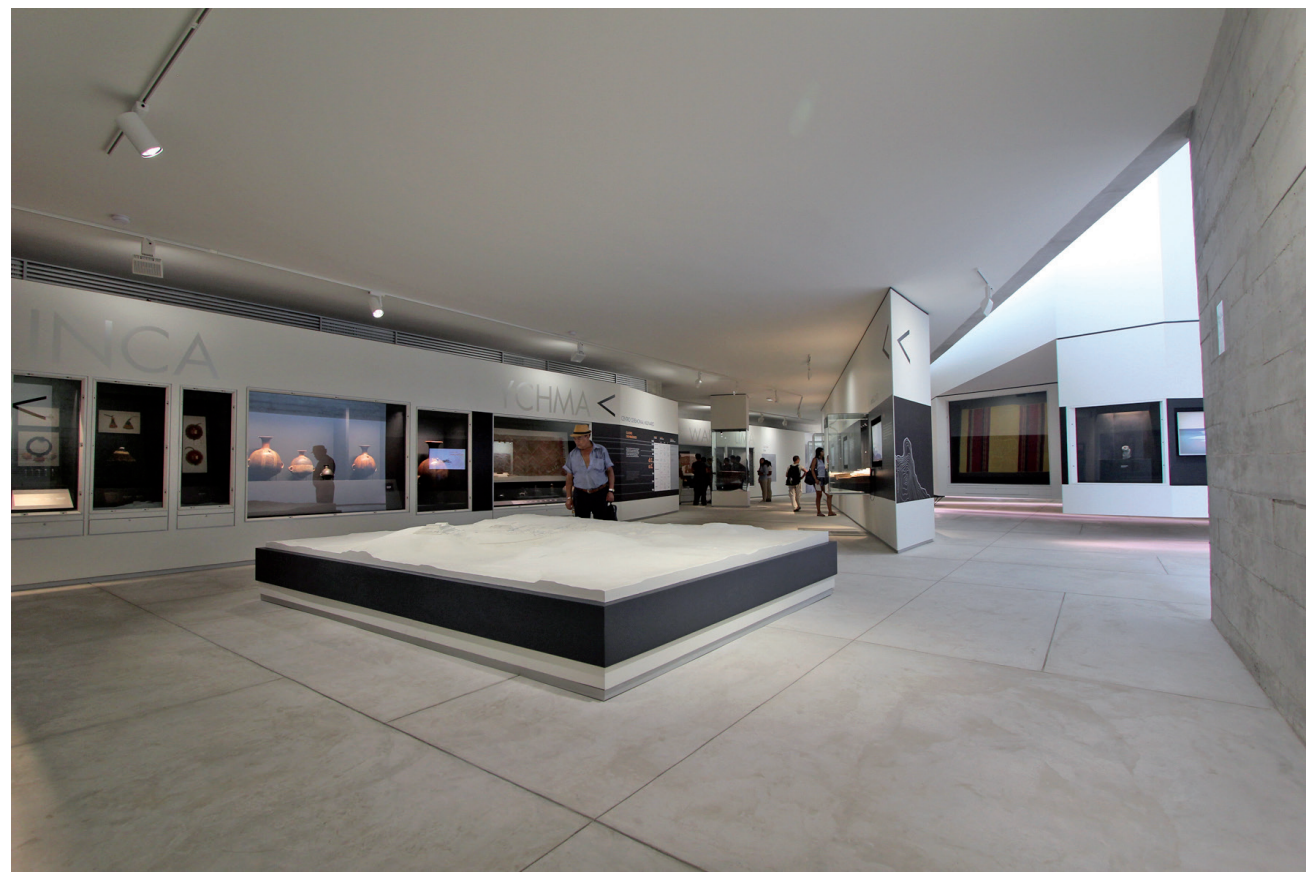

Figura 7. Vista interior del Museo Pachacamac. Archivo Museo de sitio Pachacamac. Interior view of the Pachacamac Museum. Pachacamac Site Museum Archive. 


\section{El Diseño}

\section{Comprendió:}

El espacio y los objetos. La colección del MSPAC se basa principalmente en los objetos recuperados en las investigaciones en el sitio arqueológico y la mayoría de ellas son ofrendas traídas por los peregrinos, algunas de territorios lejanos, para rendir culto al dios Pachacamac. Fue importante destacar tanto en el guion museográfico como en el diseño de la museografía este componente de sacralidad y desplazamiento, manifiestas en las libres circulaciones que se presentan en el recorrido de la exposición, sin obligar al visitante a optar por un solo camino, eliminando la idea de estancos para mostrar los objetos. Los objetos sagrados se muestran en vitrinas suspendidas, como muros levitando, colgados de los techos, en cuyos interiores, a manera de grandes hornacinas se muestran los objetos. El diseño de cada uno de estos espacios se hizo teniendo en cuenta las piezas que presentaban un reto o mayor complejidad.

La gráfica. Esta se asumió con especial interés ya que fue la oportunidad de relacionarla con la creación de la "marca Pachacamac" es decir propiciar la creación del signo que distinguiría al museo y sitio arqueológico a través del diseño gráfico y su combinación con símbolos, signos, etc., con la finalidad de identificarlo y distinguirlo de otros productos similares. El resultado, ha sido óptimo. Ha permitido establecer los colores (cuatro) que predominan en toda la muestra y en la producción de los folletos, trípticos y publicaciones, así como en la página web y redes sociales. Al color lo acompaña un estilo gráfico moderno y particular, así como un tipo de letra característico. Creemos que el público va identificando claramente el logotipo y la gráfica del nuevo museo (Figura 7).

Uno de los propósitos fundamentales del diseño museográfico fue adecuar el espacio y el relato en relación al público y en función a la protección de los objetos. Al inicio del recorrido de la exposición, el visitante dispone de información sobre la ubicación, territorio y entorno paisajístico del sitio.

En el ámbito destinado a lo sagrado, el visitante encontrará un orden que le permitirá comprender el significado del sitio arqueológico como lugar sacralizado con dos hitos importantes, por una parte la montaña sagrada Pariacaca, referente natural, lugar de peregrinaje de las poblaciones de los valles de Rimac y Lurín en la costa central. Era un $a p u$, rasgo que sacraliza el paisaje, en el tramo Xauxa Pachacamac, en cuyo extremo se encontraba el oráculo de Pachacamac, como hacedor supremo del mundo.

El sitio arqueológico de Pachacamac formaba parte de uno de los tramos principales del Qhapaq Nan, desde Pachacamac hasta Xauxa, donde circulaban peregrinos intercambiando ideas, usos y costumbres entre la costa central y las zonas alto-andinas centrales (Plan de Manejo del Santuario de Pachacamac 2012:268).

La pieza emblemática del museo, el ídolo, madero que representa a la deidad de Pachacamac, y la puerta, que, según los cronistas españoles (Pizarro 2006 [1533], Estete 1985 [1534]), cerraba el recinto sagrado donde probablemente se hallaba el ídolo, se muestran en un espacio privilegiado, relacionado con las ofrendas realizadas como culto a esta divinidad.

Destaca entre otras, la importante colección de máscaras funerarias, que según los cronistas, uno de ellos Agustín de Zárate (Plan de Manejo del Santuario de Pachacamac 2012:19), podrían corresponder a los principales personajes de la región, quienes eran enterrados en Pachacamac. Finaliza este recorrido, mostrando que el sitio era residencia de otras huacas o divinidades andinas.

El segundo ámbito, destinado a lo histórico, expresa y enseña al visitante uno de los mayores valores que el sitio arqueológico de Pachacamac atesora: su vigencia y continuidad a lo largo de 1200 años. La arquitectura monumental de las distintas épocas históricas que se concentra en el sitio arqueológico -Lima, Wari, Ychma e Inca- es testimonio de las diversas formas de culto desarrolladas sucesivamente en el centro ceremonial (Lumbreras 2017:162-165) (Curatola 2017:169).

Estos valiosos objetos de cerámica, textil, metal, material orgánico, y piedra, son presentados con información básica sobre sus dimensiones, materiales, época y lugar de procedencia.

Destacan en la secuencia, las técnicas constructivas en adobe y piedra, poniendo de manifiesto casos interesantes de continuidad en técnicas constructivas, que evidencian el funcionamiento del santuario y el respeto a su tradición a lo largo de más de mil años.

Finaliza la muestra con la presentación de los principales investigadores que han trabajado en el sitio arqueológico de Pachacamac, quienes con su dedicada y comprometida labor, han aportado al conocimiento y difusión de este importante sitio.

La exposición se despliega en un área de casi $800 \mathrm{~m}^{2}$ y cuenta con el apoyo de personal que tiene la función de supervisar las salas, ayudar a los visitantes a guiarse en el lugar y se encargan de otros tipos de actividades de funcionamiento diario ${ }^{1}$.

\section{Estudio de público}

¿Cómo ir mejorando progresivamente nuestra propuesta?, ¿cómo asegurarnos que nuestro público regrese, que se interese por el sitio arqueológico, y por lo tanto por el museo? 
La propuesta museográfica tiene actualmente, en proceso, un estudio de público para saber cuál es la reacción y obtener información de nuestros visitantes, y conocer cómo estamos transmitiendo nuestro mensaje. Además esa información fundamentará nuestra planificación.

Tenemos conocimiento que uno de los problemas generales de los estudios de público en los museos, es que los resultados no son debidamente estudiados ni aplicados a los diversos programas, por diversas causas. En el caso del MSPAC hemos contando con el apoyo de los alumnos de turismo de la Universidad Antonio Ruiz de Montoya, quienes a través de diversos instrumentos (encuestas, entrevistas, entre otras) y con el apoyo del personal del museo y de los arqueólogos, desarrollaron sus trabajos y nos permitieron al final de los cursos una información procesada y conclusiones factibles de ejecutar. De esta manera vamos evaluando nuestro trabajo y mejorándolo gracias a los comentarios del público.

Contamos además, en nuestra sala de exposición con un panel de opiniones donde los visitantes pueden expresar sus pensamientos, comentarios y críticas, los cuales son recogidos diariamente y procesados. Son expresiones cortas y puntuales pero que nos permiten medir el impacto de la visita a la sala de exposición y nos permitirá sentar las bases para evaluaciones futuras de nuestra exposición (Gob y Drouget 2010).

\section{La comunidad}

La zona que bordea el sitio arqueológico de Pachacamac fue un espacio ocupado desde la década de 1940, al inicio por los obreros que formaban parte del equipo de trabajo de Julio C. Tello, importante arqueólogo peruano de la época que trabajó en el sitio (Tello 2006:79-83) "una de las principales metrópolis del Perú, un arca de tesoros, y un registro de las diferentes etapas por las que ha pasado la historia de los tesoros en el antiguo Perú" (Tello 2012:220). En la década de 1960, cuando se produce el gran desplazamiento de poblaciones de las zonas rurales a las ciudades en busca de mejores condiciones de vida, fenómeno extendido en muchos países latinoamericanos, los linderos del sitio arqueológico son ocupados por grupos de familias venidas en su gran mayoría del sur chico de Lima (Ica). La última ocupación importante del área arqueológica se originó en las décadas de los años 1980 y 1990, como consecuencia del conflicto armado interno que azotó a nuestro país, principalmente en la sierra, obligando a muchos a migrar a la costa e impulsar invasiones en los alrededores de la zona monumental, afectando en algunos casos la zona arqueológica y los vestigios de arquitectura prehispánica.

Estos ocupantes "ilegales" sostuvieron una lucha de 30 años aproximadamente para lograr la titulación y poder inscribir sus predios como propiedad, incluso hay sectores que aún están en proceso para conseguirlo. Por estas razones, es comprensible que la comunidad del entorno no tenga una historia que vincule a sus habitantes actuales con el pasado del sitio arqueológico (Del Águila y Pozzi-Escot 2014:147). Por el contrario, la ocupación del sitio con valor patrimonial, ha significado uno de los mayores impedimentos para que puedan formalizar la propiedad de sus terrenos y acceder a los servicios básicos necesarios en toda comunidad para su adecuada habitalidad. Pero cabe resaltar que esos conflictos con las poblaciones fundadoras van desapareciendo ante la presencia de las generaciones posteriores, jóvenes que nacen y crecen en estas comunidades, y reconocen a la zona arqueológica como parte de su territorio.

Según el Plan de Manejo del año 2012 “... .la gestión del santuario propone la inclusión de la población ubicada en su entorno inmediato, con una participación activa, en beneficio del complejo arqueológico y su conservación" en concordancia con los postulados de la Nueva Museología, tratamos de llegar a una comunidad y, del "edificio" pasamos al "territorio" que será nuestroámbito de acción, lugar de residencia de la comunidad en la que nos encontramos. Tal es así que desde el año 2009 los conflictos territoriales o invasiones a terreno patrimonial, han desaparecido totalmente. Mantenemos una relación cercana con los jóvenes pobladores de los asentamientos, y a través de sus dirigencias y las diferentes actividades destinadas a niños, mujeres y jóvenes, vamos logrando su interés en valorar el sitio arqueológico de Pachacamac.

Consideramos prioritario realizar un trabajo de acercamiento con los asentamientos humanos $(\mathrm{AAHH})$ del área de amortiguamiento del santuario arqueológico, con el propósito que puedan sentirse parte de su entorno patrimonial. El museo busca promover iniciativas que les permitan mejorar su calidad de vida, comprendiendo que en sitios arqueológicos donde las evidencias arqueológicas son de difícil lectura, no tienen mucho significado para la comunidad local; y que antes de acompañar a la protección y conservación del patrimonio, priorizan la resolución de sus necesidades económicas.

En consecuencia, estamos realizando tareas que nos permitan aproximarnos a diferentes tipos de públicos. Los arqueólogos del museo y el equipo de Educación van a los AAHH del entorno para trabajar con la comunidad en el mejoramiento del paisaje y de su infraestructura educativa; asesorándolos en sus proyectos turísticos que intentan desarrollar reconociendo el potencial turístico que tiene el santuario arqueológico, para beneficio de sus poblaciones (Figura 8). La ubicación de los AAHH en los bordes del santuario, los sitúa en una inmejorable posición para apreciarlo a la distancia. Algunos asentamientos 


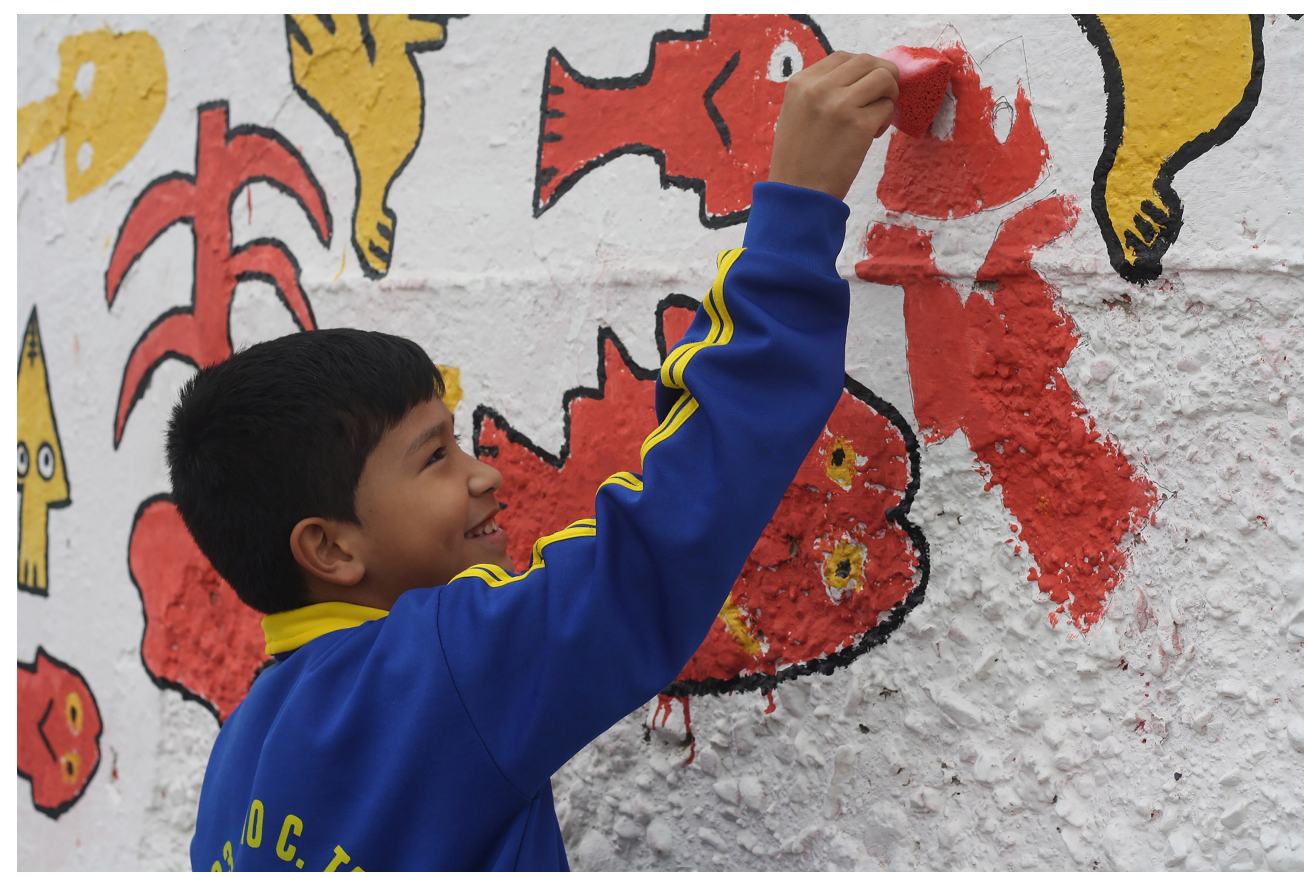

Figura 8. Trabajos con los AAHH del entorno del sitio arqueológico. Foto: Rommel Angeles Falcón.

Work with the AAHH of the the surroundings of the archaeological site. Photo: Rommel Angeles-Falcón.

han instalado un circuito turístico en sus calles, que consiste en observar al santuario desde lejos. Este circuito ha movilizado a vecinos a una oferta de comida principalmente y una oferta de ferias artesanales los fines de semana.

En el Plan de Manejo del Santuario de Pachacamac se ha incorporado la propuesta de un "Parque Cultural Pachacamac", proyecto elaborado por el arquitecto José Canziani, que implica el acondicionamiento de los límites del santuario para su puesta en uso social. De esta manera se propone una franja habilitada dentro de algunos límites del santuario que colindan con los AAHH del entorno, donde se puedan desarrollar "actividades recreativas y culturales, generando ... recorridos tanto de paseos peatonales, como de corredores y ciclismo en todo su perímetro" (Plan de Manejo del Santuario de Pachacamac 2012:322).

Esta es una de las razones principales por las cuales trabajamos en el museo Pachacamac diferentes tipos de proyectos y actividades con los AAHH que se encuentran dentro del área de amortiguamiento, o circundantes al sitio, para contribuir a forjar una identidad que les permita enfrentarse al futuro de manera diferente. Pero por otro lado, la presión urbana es sumamente fuerte y los linderos del complejo arqueológico son bastante frágiles, por lo que es imprescindible el trabajo con la comunidad vecina al santuario.
Una de las maneras para conservar nuestros sitios arqueológicos, constantemente amenazados por los ocupantes ilegales de terreno, es hacer participar a la comunidad del entorno en las diferentes actividades del museo, para poder ser un "museo sostenible" siguiendo la definición de DeCarli (2004). Para ello según la autora

Es toda institución que realiza actividades de investigación, preservación, comunicación y reactivación del patrimonio a través de una moderna gestión museológica adecuada a los requerimientos de su entorno; y que con el fin de generar un desarrollo local sostenible y beneficios para el museo, lleva a cabo conjuntamente con miembros de las comunidades, proyectos y actividades de preservación activa ejerciendo un usufructo responsable de los recursos patrimoniales (DeCarli 2004:160).

De esta manera, el museo de Pachacamac no solo tiene una nueva arquitectura, con una nueva propuesta museográfica que significa un gran cambio para el sitio, sino también para la comunidad del entorno.

La belleza paisajística y la riqueza iconográfica del sitio y de los vestigios encontrados han inspirado creaciones contemporáneas de artistas plásticos, artesanos, fotógrafos y arquitectos. La conservación, 
puesta en valor y uso público del complejo monumental hoy en día fortalece en la comunidad una relación de identidad cultural, y constituye una importante herramienta de construcción de autoestima, participación y desarrollo social.

Tal vez una de las iniciativas más importantes de relación con la comunidad del entorno ha sido el proyecto de Desarrollo Comunitario, financiado por Sustainable Preservation Initiative (SPI). Este proyecto cuenta con expertos profesionales -profesores, miembros de empresas y formadores (la empresa KANI es uno de los principales asesores)que capacitan en diferentes áreas a los participantes involucrados en el proyecto teniendo como objetivos específicos:

(1) Incorporar y socializar a la comunidad los valores del santuario de Pachacamac (Figura 9).

(2) Contribuir al fortalecimiento de la identidad local de las personas integrantes de los talleres.

(3) Crear productos con identidad: los productos deben estar relacionados con la historia del santuario de Pachacamac.

El proyecto se fundamenta en tres ejes: patrimonio, producción artesanal, y formación. El Programa de formación continua nos ha permitido capacitar a los participantes en la elaboración de objetos utilitarios y decorativos a partir de la investigación y recreación de la iconografía de Pachacamac con el propósito de gestar a mediano plazo una empresa comunitaria responsable y sostenible.

Los principales beneficiarios son dirigentes vecinales, padres, madres de familia y jóvenes de los AAHH Primero de Diciembre, Villa Alejandro, Marta Milagros y UPIS San José de Lurín. También se han integrado señoras de los distritos de Villa El Salvador y Pachacamac.

El proyecto nos ha permitido consolidar un grupo de mujeres organizadas, vinculándolas al trabajo del MSPAC a lo largo de tres años de capacitaciones e intercambio de experiencias. Al inicio hemos capacitado alrededor de 60 personas, en torno a la importancia del santuario arqueológico, continuamos con capacitaciones acerca de las posibilidades del turismo y oportunidades de negocios. El segundo año el grupo se redujo participando las mujeres más interesadas con las cuales seguimos trabajando hasta hoy.

Este grupo ha podido constituirse en Asociación Civil sin fines de lucro, SISAN que significa -floreceren quechua. Representa a una organización de mujeres emprendedoras, que generan ingresos que les permite tener un pequeño fondo a fin de mes a cada una de ellas y contribuyen a la mejora de la economía de sus hogares y por consiguiente a sus condiciones de vida.

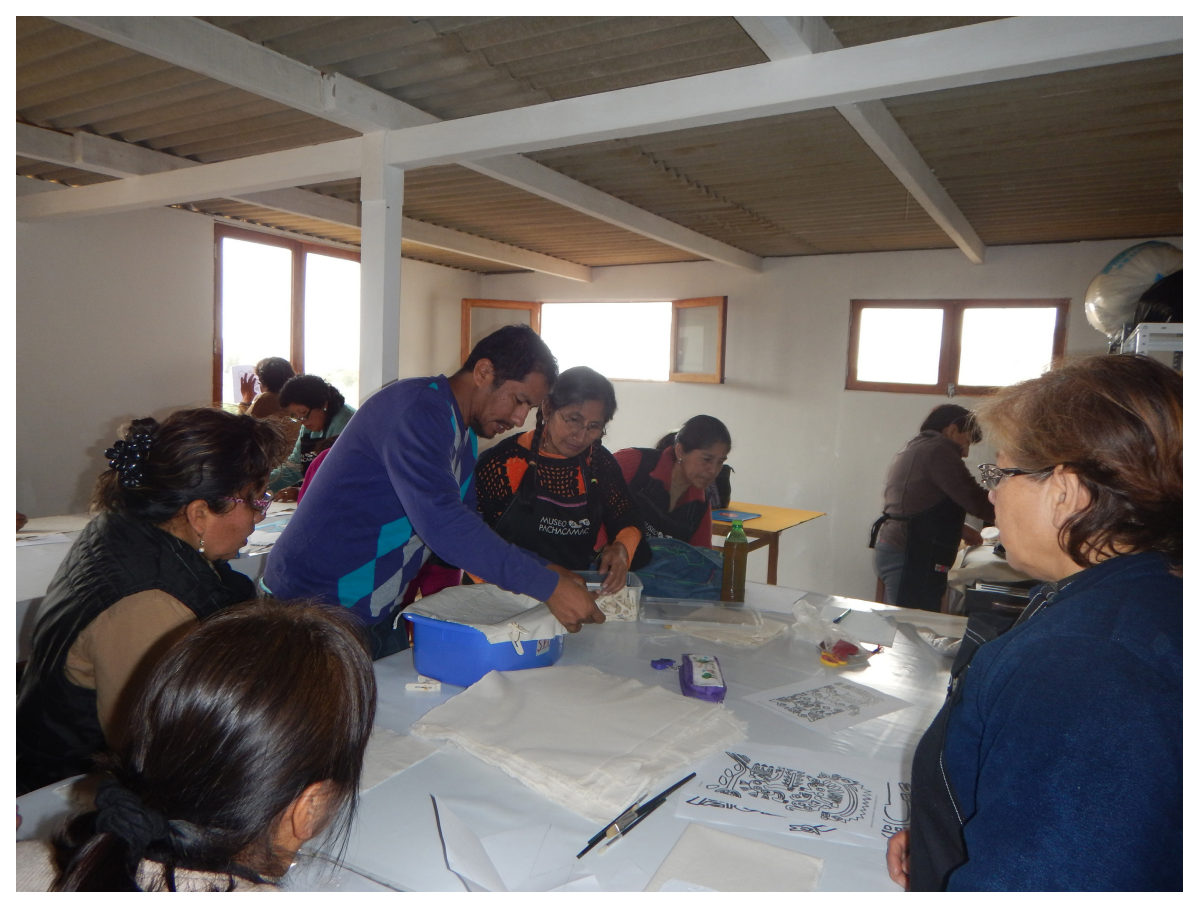

Figura 9. Programa de Desarrollo Comunitario. Archivo Museo de sitio Pachacamac.

Community Development Program. Pachacamac Site Museum Archive. 
A través de talleres de Gestión de empresa, Desarrollo de productos, Evaluación de calidad de productos y cotización, Dinámica de trabajo en equipo, Liderazgo y Políticas de empresas han desarrollado sus capacidades y puesto en marcha su actividad productiva (Figura 10).

Complementariamente, el MSPAC, gracias al apoyo de "Turismo Cuida", ha podido continuar con la capacitación de las mujeres de SISAN. Este proyecto nos ha permitido intercambiar experiencias con el Museo de Túcume, ubicado en la costa norte del país con características similares al MSPAC, el cual desarrolla un proyecto con los artesanos de la zona que disponen de gran experiencia en "teñido en reserva", técnica ancestral que utiliza tintes de diferentes colores y consiste en cubrir o tapar con parafina los diseños, reservando de esta manera los colores que se desea obtener. La tela en la que se tiñe es de algodón.

Con el propósito de propiciar la variedad de los productos que elaboran las artesanas de SISAN, y mantenerse en el mercado con propuestas novedosas, se consideró importante el aprendizaje de nuevas técnicas para incrementar la diversidad de sus productos. Qué mejores maestros que aquellos artesanos como ellas, los cuales han pasado por las mismas experiencias y procesos de emprendimientos (Figura 11). Eneste primer taller se expusieron conocimientos previos a la técnica de teñido en reserva, se identificaron los materiales a utilizar y se aprendieron sus usos. Este proyecto incluye también la elaboración de una propuesta de catálogo de objetos que podrán ser elaborados a partir de la técnica de teñido en reserva aprendida, diversificando de esta manera la producción para la venta.

Antiguamente, las poblaciones veían al santuario como un espacio ajeno y sin utilidad real para su conocimiento y desarrollo, hoy, la mirada es distinta y este se viene convirtiendo en un lugar de conocimiento y de oportunidades de desarrollo personal y económico. Más aún, la interacción entre las mismas artesanas ha permitido relaciones de afecto y tolerancia, reconociendo las capacidades diferentes de cada una de ellas en diferentes tareas y creándose lazos profundos de solidaridad. Estos sentimientos los manifiestan también hacia el museo y el santuario.

El MSPAC está siguiendo las propuestas discutidas en la Mesa de Santiago de Chile en el año de 1972, y luego en la Declaración de Oaxtepec en México el año 1984, donde se señaló la necesidad de la participación comunitaria tanto en el patrimonio como en los museos y la utilización de éstos como una herramienta de desarrollo.

Conjuntamente al proyecto de Desarrollo Comunitario, se ha diseñado un programa de Talleres Educativos, importante dentro de nuestro trabajo, ya

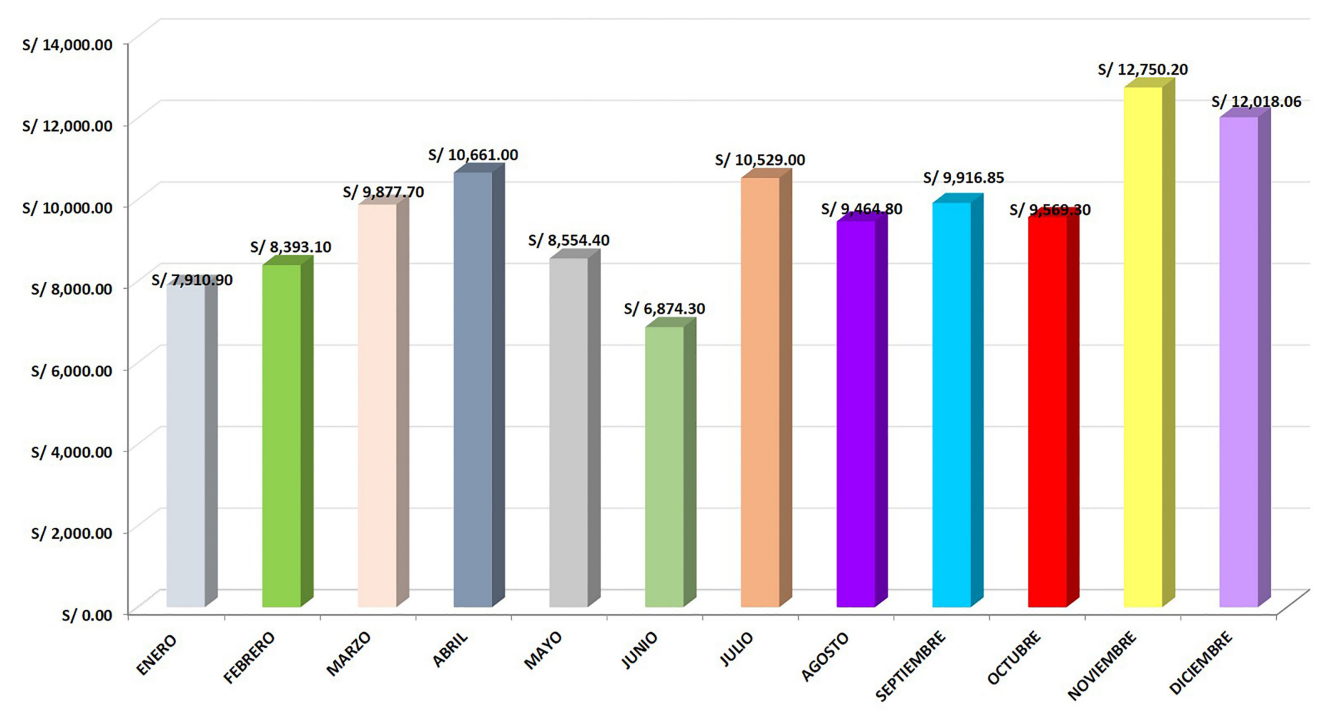

Figura 10. Ventas anuales (en moneda peruana) de la Asociación SISAN. Archivo Museo de sitio Pachacamac.

Annual sales (in Peruvian currency) of the SISAN Association. Pachacamac Site Museum Archive. 


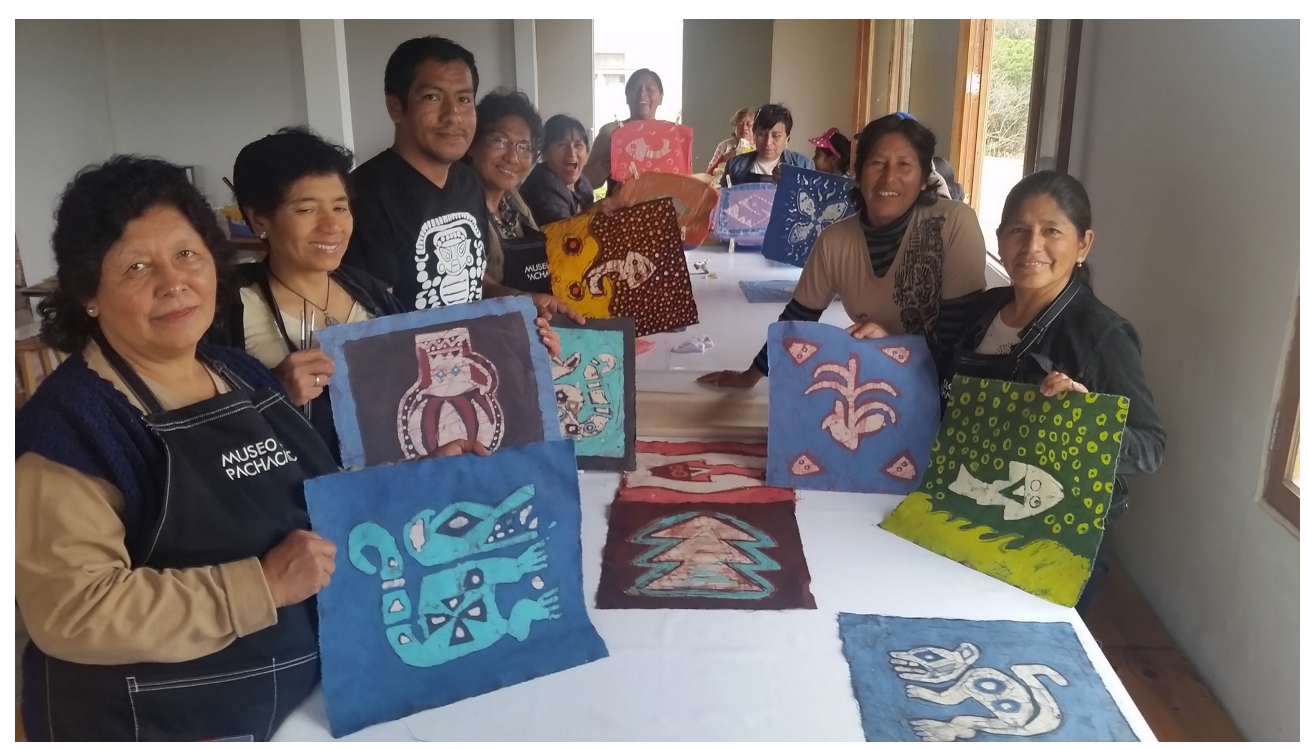

Figura 11. Taller de teñido en reserva. Archivo Museo de sitio Pachacamac.

Dyeing in reserve Workshop. Pachacamac Site Museum Archive.

que el $40 \%$ de nuestros visitantes son escolares, y este acercamiento a la población educativa nos permite crear vínculos entre patrimonio, museo y comunidad.

El equipo de educación del MSPAC realiza labores de concientización y participación con la comunidad, tanto en la protección y conservación del sitio como en potenciar sus valores educativos, históricos y de utilidad para las poblaciones actuales. El programa de actividades en y con los colegios y las poblaciones del entorno dirigido a estudiantes y a la comunidad en general, consiste en talleres dinámicos de educación patrimonial, tratando de crear conciencia entre los jóvenes sobre la importancia de la protección de nuestro patrimonio (Gómez Martínez 2011:161). En el año 2016 logramos capacitar a 70 familias y más de 1500 estudiantes de educación primaria, mayoritariamente en talleres diferenciados, que se realizaron durante un mes a lo largo del año en el Museo (Figura 12, Tabla 1).

Los talleres seleccionados tienen relación con el sitio y se realizan con el mismo grupo durante todo un mes:

\section{Taller de quipus}

Los quipus fueron de gran importancia para la administración inca de las comarcas sujetas al imperio. Eran instrumentos de contabilidad, usados para registrar y transmitir información cuantitativa importante, expresada a manera de nudos sobre cuerdas colgantes (Urton 2014:9). La importancia del santuario para los incas está demostrada por el hallazgo de varios quipus en el sitio (Urton 2014:15) por lo tanto el conocimiento sobre este sistema contable incaico nos permite acercarnos al estudio de los incas en Pachacamac. Los niños aprenden anudando sus propios quipus.

\section{El ídolo de Pachacamac}

El ídolo encontrado en 1938 en los escalonamientos del Templo Pintado (Lumbreras 2017:150), es una de las piezas emblemáticas del museo. Se trata de un personaje bifronte tallado en un madero, tiene tres secciones: las dos primeras reúnen una serie de imágenes que tal vez se refieren a una narrativa de la cosmovisión de esta deidad; la tercera sección es un vástago sin decoración que permitiría al madero ser hincado en la tierra de forma vertical. Usando réplicas en madera del ídolo, y luego de la visita al museo, los alumnos tallan en jabón el ídolo de Pachacamac.

\section{Conociendo el Santuario Arqueológico de Pachacamac}

El sitio arqueológico permite al visitante conocer los edificios y espacios arqueológicos emblemáticos, de diferentes épocas. Los niños en visitas guiadas recorren este circuito y en cada punto se les explica la importancia del lugar (Figura 13).

\section{EI Templo Pintado y el taller de iconografía}

Las pocas pinturas que quedan con diseños en colores rojo, amarillo, negro y verde, se encuentran en parte en el Templo Pintado, distinguiéndose diseños de 


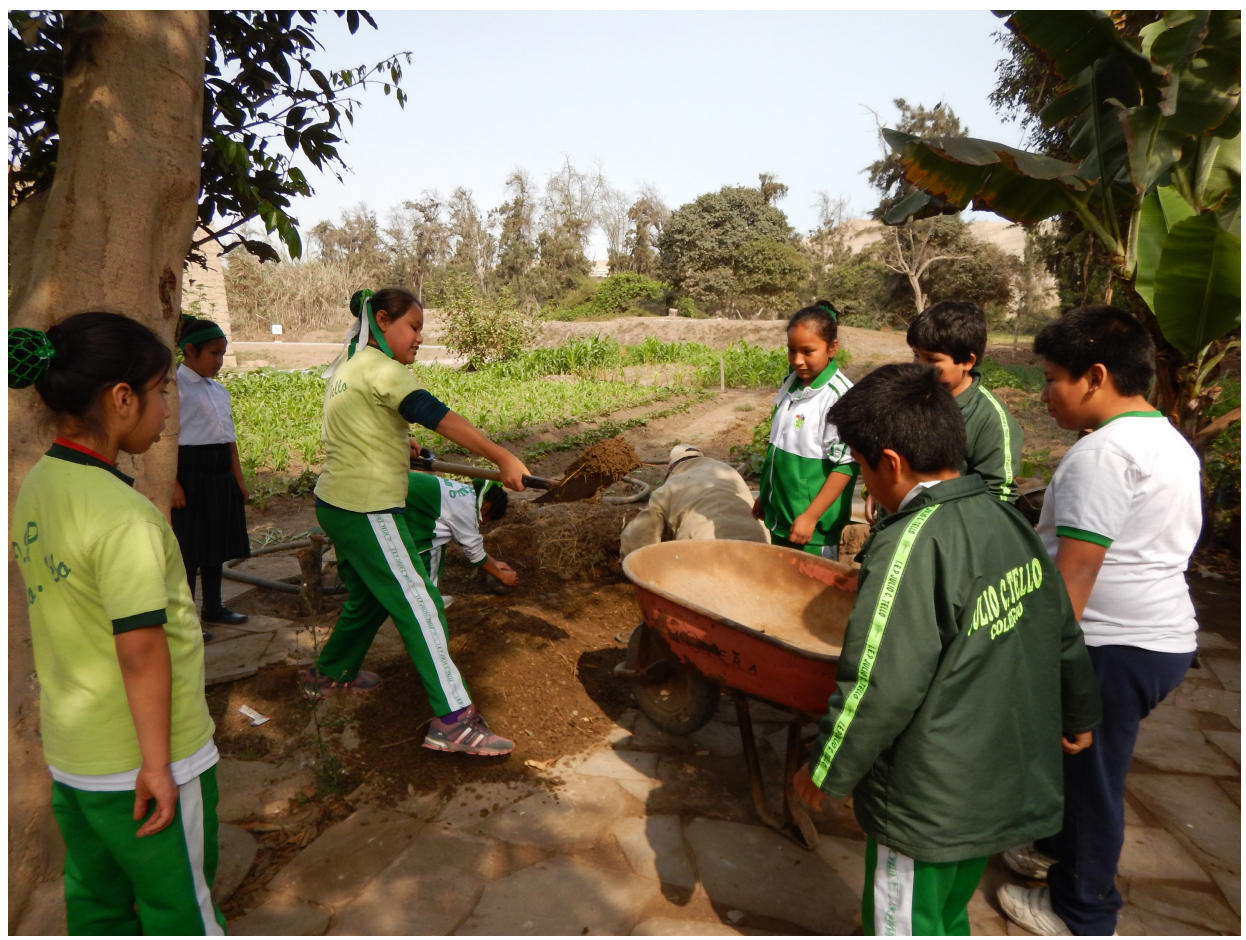

Figura 12. Programa Educativo. Archivo Museo de sitio Pachacamac.

Educational Program. Pachacamac Site Museum Archive.

Tabla 1. Talleres educativos, año 2018. Museo un recurso para la educación en la diversidad que se realiza a través de la experiencia y que refuerza nuestra identidad.

Educational workshops, 2018. The Museum, a resource for the education in diversity through experience and that strengthens our identity.

\begin{tabular}{|c|c|c|c|c|}
\hline & Colegios/Instituciones & Edad/Grado & $\begin{array}{l}\text { Número de } \\
\text { Participantes }\end{array}$ & Descripción de actividades \\
\hline Taller de verano & $\begin{array}{l}\text { I.E.P Alma Mater Upis San } \\
\text { José - Lurín }\end{array}$ & $\begin{array}{l}\text { 3ero y 6to Primaria. } \\
\text { 1ero y } 2 \text { do Secundaria }\end{array}$ & 46 niños & \multirow{10}{*}{$\begin{array}{l}\text { Visita a la sala de exposición permanente. } \\
\text { Diseños de íconos del santuario. } \\
\text { Representación de quipus en cuerdas. } \\
\text { Visita por la Ruta de Peregrinos. } \\
\text { Actividades en la Intichacra (sembrar, } \\
\text { cosechar, regar, compost, entre otros). } \\
\text { Reconocimiento de cultivos. } \\
\text { Revisión y apreciación del mito "El misterio } \\
\text { de las islas de Pachacamac". } \\
\text { Representación y puesta en escena del mito. } \\
\text { Taller de simulación de excavación } \\
\text { arqueológica en campo. } \\
\text { Taller de conservación de réplicas de } \\
\text { cerámica. } \\
\text { Taller de preparación de montaje para una } \\
\text { exposición. } \\
\text { Taller de línea de tiempo de las culturas } \\
\text { desarrolladas en el sitio arqueológico. } \\
\text { Guiado interactivo en el museo y sitio } \\
\text { arqueológico. } \\
\text { Realización del taller de iconografía y } \\
\text { elaboración de una vasija réplica en arcilla. } \\
\text { Visitar y conocer los ambientes del museo. } \\
\text { Uso de piezas réplicas (vasijas, máscaras, } \\
\text { conchas, entre otras). }\end{array}$} \\
\hline \multirow{5}{*}{$\begin{array}{l}\text { Taller Educativo } \\
\text { con la comunidad }\end{array}$} & $\begin{array}{l}\text { I.E.P. Reyna de los Ángeles } \\
\text {-Villa Alejandro - Lurín }\end{array}$ & $\begin{array}{l}\text { 3ero, 4to Primaria. } \\
\text { 1ero y 2do Secundaria }\end{array}$ & 86 estudiantes & \\
\hline & $\begin{array}{c}\text { I.E.N. Julio C. Tello } 6023 \\
\text { Lurín }\end{array}$ & $\begin{array}{l}\text { 3ero, 4to y 6to Primaria. } \\
\text { 1ero y 3ero Secundaria }\end{array}$ & 289 estudiantes & \\
\hline & $\begin{array}{c}\text { I.E.N. Santa María Reyna } \\
\text { Quebrada Verde }\end{array}$ & $\begin{array}{l}\text { 3ero, } 4 \text { to, } 5 \text { to y } 6 \text { to } \\
\text { Primaria }\end{array}$ & 109 estudiantes & \\
\hline & $\begin{array}{l}\text { I.E.P. Coprodeli Cristo Salva- } \\
\text { dor- Villa Alejandro - Lurín }\end{array}$ & $\begin{array}{l}\text { 4to Primaria. } \\
\text { 1ero Secundaria }\end{array}$ & 47 estudiantes & \\
\hline & $\begin{array}{l}\text { I.E.P. Enrique Camino Brent } \\
\text { - Upis San José }\end{array}$ & 4to y 6to de Primaria & 21 estudiantes & \\
\hline Taller Educativo & $\begin{array}{c}\text { I.E.P. Laurent Clerc - } \\
\text { Salamanca (con habilidades } \\
\text { especiales) }\end{array}$ & Primaria & 16 estudiantes & \\
\hline Taller Educativo & CEBE San Francisco de Asís & 7 a 12 años & 26 estudiantes & \\
\hline Taller Educativo & $\begin{array}{c}\text { Colegio Fernando Wiesse } \\
\text { Eslava (con habilidades } \\
\text { especiales) }\end{array}$ & 8 a 10 años & 15 estudiantes & \\
\hline Taller Educativo & Grupo de familia & 14 a 18 años & 20 jóvenes & \\
\hline
\end{tabular}




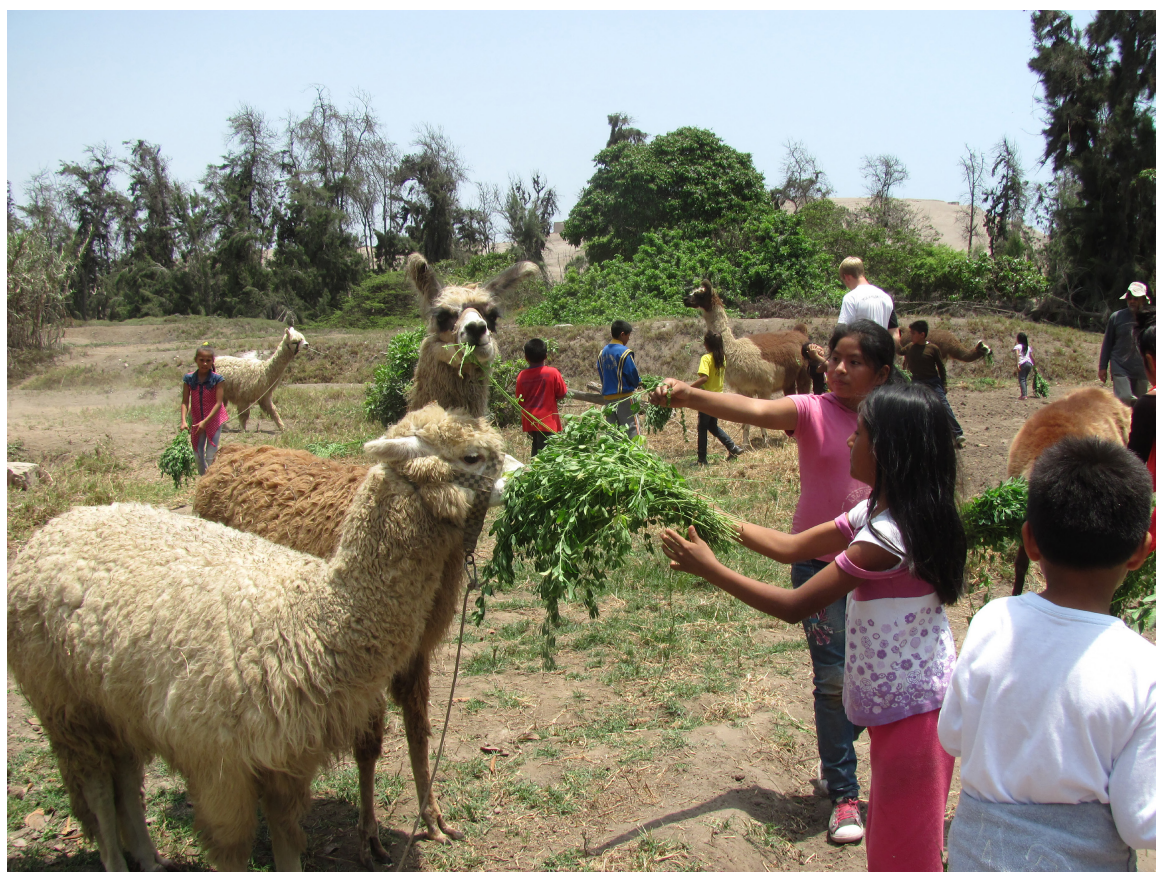

Figura 13. Visitas guiadas a niños. Archivo Museo de sitio Pachacamac.

Guided tours for children. Pachacamac Site Museum Archive.

aves de perfil, peces en movimiento, plantas y personajes en las graderías, testimonio de la iconografía de la época.

A partir de estos colores y diseños representados en el Templo Pintado, los niños pintan o recrean escenas sobre tela los diseños relacionados a las deidades de Pachacamac.

\section{Las ofrendas}

Una actividad importante consiste en que los niños conozcan las tradiciones andinas, como las ofrendas a la pachamama, importante ceremonia en el mundo andino actual, donde se ofrece a la madre tierra, pequeñas ofrendas para garantizar buenas cosechas o desear buen tiempo para los cultivos: alimentos y objetos, así como brindar con la tierra chicha de jora, bebida elaborada en base a maíz, tradición que perdura hasta hoy. Los niños llevan frutos, flores, granos y pedidos para ofrecerlos.

\section{La línea de tiempo}

La historia del Perú prehispánico se remonta a miles de años. Representar esos años y el proceso histórico es difícil, por ello se recurre a elementos de la historia que han caracterizado a cada uno de esos momentos. Para ello, los alumnos toman elementos de las culturas identificadas por los arqueólogos a través del tiempo y los plasman en una hoja de papel que representa siglos de nuestra historia.

\section{El mito}

El sitio arqueológico de Pachacamac es un espacio sagrado, sobre el cual discurren historias, leyendas y mitos que hasta hoy subsisten en documentos y en la memoria colectiva. Un conocido mito sobre el origen de los peces y de los atributos de los principales animales andinos, donde interactúan dioses y diosas, fue recopilado en la sierra de Lima (Avila 1966:23-29). La diosa huyendo llega a Pachacamac, se arroja al mar con su hija y se transforma en las islas que hoy pueden verse en el litoral. El mito es trabajado mediante un libro objeto en el cual los alumnos representan, recortan y pintan pasajes del mito.

Por último, como parte de nuestro trabajo educativo hemos editado publicaciones de orden académico (Santuario arqueológico de Pachacamac: investigaciones en la ruta de los peregrinos. Ministerio de Cultura 2018, Urpiwachaq: gestión y puesta en valor de la laguna. Ministerio de Cultura - Universidad del Pacifico, 2015) y guías didácticas al servicio de los docentes (Descubriendo el santuario de Pachacamac. Guía para maestros, 2013; Descubriendo nuestro 
pasado prehispánico. Cartilla de trabajo para maestros y estudiantes, 2012). De igual manera se llevan a cabo visitas pedagógicas y proyectos pilotos con escuelas del entorno (Pachacamac: descubriendo mi museo. Ministerio de Cultura. Proyecto Qhapaq Ñan, UNESCO. Lima 2018). El reto de educadores y mediadores culturales es acercar a los escolares al sitio arqueológico para interrelacionar los significados que otorgan la escuela, las instituciones, los profesionales responsables de la conservación y puesta en valor del sitio, con los significados que el público escolar tiene (Figura 14). A partir de ese encuentro se busca construir juntos nuevos significados, y encontrar sentido a la preservación y respeto al patrimonio que lo rodea, haciendo suyos los valores que representa (Figura 15).

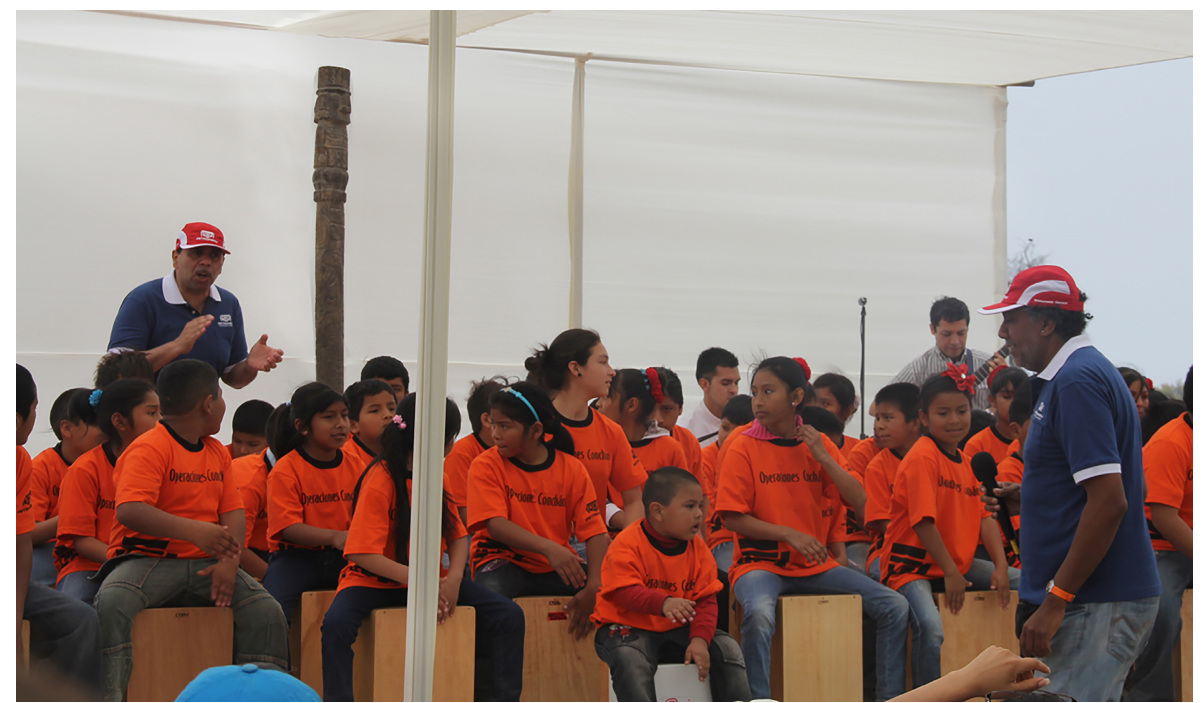

Figura 14.Talleres de expresiones artísticas con el patrimonio. Archivo Museo de sitio Pachacamac. Workshops of artistic expressions with the heritage. Pachacamac Site Museum Archive.

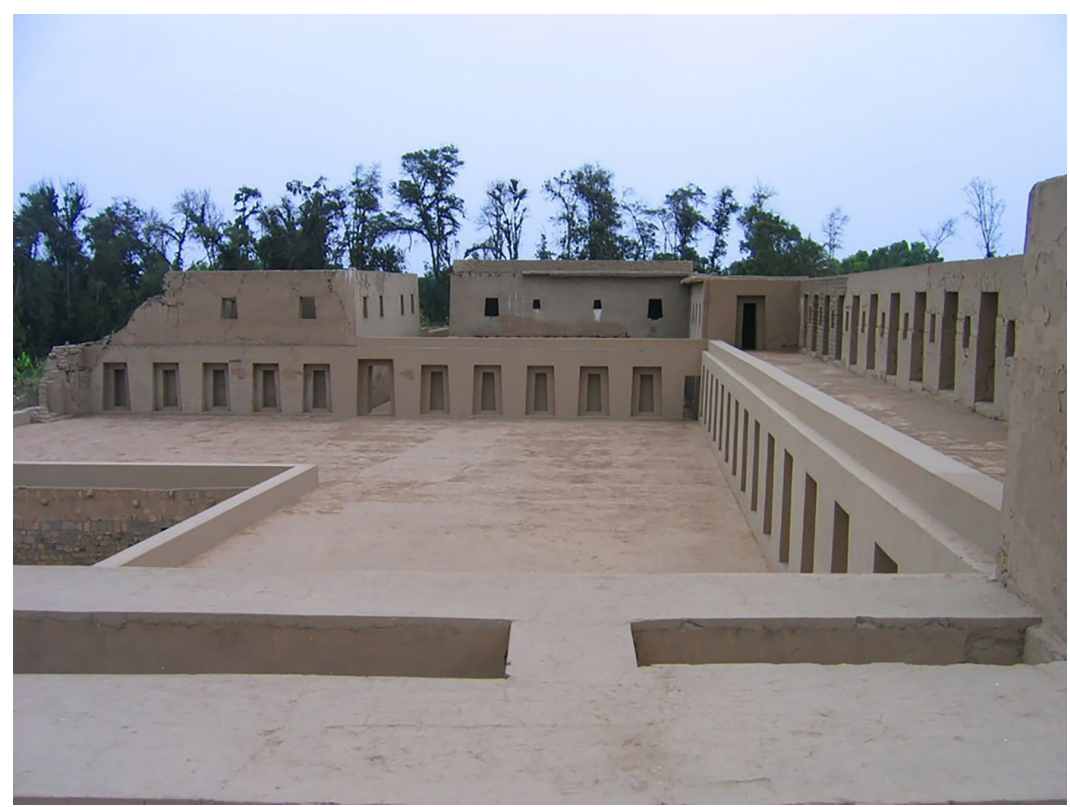

Figura 15. El reto es encontrar juntos el sentido de preservación y respeto al patrimonio que nos rodea. Archivo Museo de sitio Pachacamac.

The challenge is to find together the sense of preservation and respect for the heritage that surrounds us. Pachacamac Site Museum Archive. 


\section{Conclusiones}

El proceso de inserción y de reconocimiento del patrimonio arqueológico, tal como ha sido en el caso del museo y sitio arqueológico de Pachacamac, ha sido largo y complejo. Son más de 10 años ofreciendo a la comunidad en general diferentes actividades que han ido aumentando en el tiempo por diversas razones: La primera es, que nuestra capacidad de convocatoria ha aumentado, es decir que hemos logrado credibilidad y resultados satisfactorios para los participantes y público en general. Segundo, hemos logrado aplicar a diferentes fondos de la cooperación internacional, lo que nos permite la modernización y mejoras en nuestra atención, apuntando a ser un museo moderno. Tercero: se ha logrado una sostenida gestión que ha permitido la conservación e investigación del sitio arqueológico, siendo uno de sus logros contar con un Plan de Manejo del santuario, políticas de intervención que dirigen las acciones de conservación, investigación, puesta en valor y uso social del sitio.

Reconocemos que este proceso no ha terminado, pero el avance con la población, instituciones, empresas y el Ministerio de Cultura, al cual pertenecemos ha sido importante. Estamos trabajando ahora para ser un museo inclusivo, para todos, esta es nuestra próxima meta, que el Museo Pachacamac pueda ser un punto de referencia para las personas con capacidades especiales puedan disfrutar de nuestra cultura, de su cultura. Estamos convencidos que la participación de un equipo multidisciplinar es una de las bases para la continuidad y sostenibilidad del museo Pachacamac.

Agradecimientos: Asociación de Artesanas SISAN, SPI, Turismo Cuida, Kani, Museo de sitio de Túcume.

\section{Referencias Citadas}

Avila, F. 2012. Dioses y Hombres de Huarochiri: Narración Quechua Recogida por Francisco de Avila (¿1598?). Segunda edición. Instituto de Estudios Peruanos, Lima.

Chaumier, S. 2003. Des Musées en Quête d'Identité. Écomusée Versus Technomusée. L'Harmattan, Paris.

Curatola, M. 2017. Los oráculos de los confines del mundo. Pachacamac, Titicaca y el Inca Tupac Yupanqui. En Pachacamac el Oráculo en el Horizonte Marino del Sol Poniente, editado por D. Pozzi-Escot, pp. 187-197. Banco de Crédito, Lima.

DeCarli, G. 2004. Un Museo Sostenible. Museo y Comunidad en la Preservación Activa de su Patrimonio. Ed. Oficina de la UNESCO para América Central, San José de Costa Rica.

Del Águila, C. y D. Pozzi-Escot 2014. Pachacamac: apropiación social del patrimonio. En Museos y Bien Común. IX Encuentro Regional CecaICOM, Comié Peruano del ICOM, L. Repetto, pp. 146-153, Lima.

Estete 1985 [1534]. La relación del viaje que hizo el señor capitán Hernando Pizarro por mando del señor Gobernador, su hermano, desde el pueblo de Caxamalca a Parcama y de allí a Jauja. Francisco de Xerez. Verdadera relación de la conquista del Perú, editado por C. Bravo, 130-148. Madrid: Historia 16.

ICOM 2017- Código de deontología del ICOM para los museos. https://icom.museum/wp-content/uploads/2018/07/ICOMcodigo-Es-web-1.pdf (18 marzo 2019).

ICOM 2017. http://icom.museum/es/news/the-challenge-ofrevising-themuseum-definition/

García Canclini, N. 1999. Los usos sociales del Patrimonio cultural. En Patrimonio Etnológico. Nuevas Perspectivas de Estudio, editado por E. Aguilar Criado, pp. 16-33. Consejería de Cultura, Junta de Andalucía, Andalucía.

Gob,A. y N. Drouguet 2010. La Muséologie. Histoire, Développements, enjeux Actuels. Troisiéme édition. Armand Colin, Paris.
Gómez Martínez, A.M. 2011. La utilización del patrimonio local como fórmula educativa y de puesta en valor del mismo. IV Congreso de Educación, Museos y Patrimonio. Memorias de Hoy, Aprendizajes del Futuro, pp. 161-169. DIBAM, ICOM, CECA, Santiago.

Lumbreras, L.G. 2017. Pachacamac, el ídolo. En Pachacamac el Oráculo en el Horizonte Marino del Sol Poniente, editado por D. Pozzi-Escot, pp. 162-165. Banco de Crédito, Lima.

Pizarro, P. 2006 [1533]. Carta relación de Hernando Pizarro a los oidores de la Audiencia de Santo Domingo sobre la conquista del Perú. Pachacamac pp.12-14. Instituto Nacional de Cultura, Lima.

Plan de Manejo del Santuario Arqueológico de Pachacamac 2012. Resumen Ejecutivo. UNESCO, Plan COPESCO Nacional y Ministerio de Cultura, Lima.

Pozzi-Escot, D. 2017. Un espacio sagrado milenario. En El Oráculo en el Horizonte Marino del Sol Poniente, editado por D. Pozzi-Escot, pp. 2-31 Banco de Crédito, Lima.

Prensky, M. 2010. Nativos e Inmigrantes Digitales. Institución Educativa SEK. htpp://www.marcprensky.com/writing/Prensky-NA TIVOSINMIGRANTESDIGITALES(SEK).pdf (15 marzo 2019).

Scavia, B. 2013. Protocolo de embalaje y traslado. Museo de sitio de Pachacamac, ciudad. http://pachacamac.cultura.pe/sites/default/files/ documento_final_protocolo_embalaje_-_may-junio_2013.pdf.

Swain, H. 2007. An Introduction to Museum Archaeology. Cambridge University Press, Cambridge.

Tello, J.C. 2006. Pachacamac. En Pachacamac, editado por el Instituto Nacional de Cultura, pp. 79-83. Instituto Nacional de Cultura, Lima.

Tello, J.C 2012. Arqueología e historia de Pachacamac. Cuadernos de Investigación del Archivo Tello $\mathrm{N}^{\circ} 10$. Museo de Arqueología y Antropología. Universidad Nacional Mayor de San Marcos, Lima.

\section{Nota}

${ }^{1}$ Es importante mencionar que los fondos para la construcción del Museo de sitio Pachacamac provinieron del Proyecto
Qhapaq Nan Sede Nacional y bordearon los 12 millones de soles (poco más de 3,5 millones de dólares americanos). 
